\title{
Bonificações no setor de varejo - receita ou redução de custos?
}

\begin{abstract}
Jerônimo Antunes
Doutorado em Contabilidade e Controladoria pela Faculdade de Economia, Administração e Contabilidade da Universidade de São Paulo - FEA/USP Professor da Faculdade de Economia, Administração e Contabilidade da Universidade de São Paulo - FEA/USP

Avenida Prof. Luciano Gualberto, 908. Cidade Universitária. São Paulo/SP E-mail: jantunes@usp.br

Vinícius de Castro Alves Sampaio Mestrado em andamento em Controladoria pela Universidade Federal do Ceará - UFC Av. da Universidade, 2.431. Benfica. Fortaleza. Ceará/CE E-mail: viniciussampaio@hotmail com
\end{abstract}

\section{RESUMO}

Este trabalho tem por objetivo identificar as formas comerciais mais comuns de bonificações concedidas pelos fornecedores ao setor de varejo e as implicações contábeis e fiscais decorrentes desta prática comercial. É enfatizado que não há regras ou posicionamentos estabelecidos nas normas brasileiras de contabilidade vigentes atualmente, quanto ao tratamento e registro de determinados tipos de acordos comerciais comumente empregados no cotidiano dessas entidades. Em decorrência desta lacuna, tais empresas, em muitas circunstâncias, tratam estas bonificações como receita e, portanto, pagam impostos e contribuições sociais que, como se verificará, nem sempre são devidos, além de ir de encontro ao correto reconhecimento contábil pela essência dessas transações. A proposta deste estudo, além de destacar a importância e a complexidade deste tema, é o de apresentar algumas orientações contábeis, mas não esgotá-las, tomando por base os procedimentos já adotados em outros países, a legislação fiscal brasileira e, obviamente, os princípios contábeis brasileiros. Conclui-se o trabalho reconhecendo que as bonificações são instrumentos importantes nos processos de negociações junto aos fornecedores do setor de varejo, mas que, para o seu correto reconhecimento nos demonstrativos contábeis, as empresas deverão formalizar estes acordos e estruturar alguns controles para identificação e associação dessas bonificações às mercadorias adquiridas.

Palavras-chave: Bonificações sobre mercadorias, Descontos condicionais, Descontos incondicionais, Acordos comerciais, Fornecedor, Cliente. 


\section{ABSTRACT}

This paper aims at identifying the most common forms of considerations given by vendors to customers as well as the accounting and taxes implications of this commercial act. It emphasizes that there are no rules established in the current Brazilian norms of accounting about the treatment and register of specific kinds of commercial agreements often made by these companies. As a result of this gap, such companies, in many circumstances, treat these considerations as revenues and, therefore, pay taxes and social contributions, which, as it will be verified, is not always necessary. Besides, these companies also fail on following the correct accounting recognitions for the essence of these transactions. The aim of this study is not only to highlight the importance and the complexity of this subject, but also to present some accounting suggestions, although not meaning to exhaust them, taking as a base the procedures already adopted in other countries, the Brazilian taxes legislation, and the Brazilian Generally Accepted Accounting Principles. This paper is concluded with the recognition that considerations are important instruments of purchase to vendors, but in order to recognize them correctly in the financial statements, the companies must formalize these agreements and adopt some instruments of control for identification and association of their considerations to the purchased vendor's products.

Key-words: Considerations. Conditional Discounts, Unconditional Discounts, Commercial Agreements, Vendor, Customer.

\section{INTRODUÇÃO}

A oportunidade de, em um mesmo local, o consumidor ter acesso ao conjunto de bens desejado tais como: alimentos, produtos de higiene, etc., lastreou o conceito de auto-serviço difundido no início da década de 1930 nos Estados Unidos pelas redes de lojas King Kuller e Big Bear.

Uma das principais características do setor varejista é o seu crescente dinamismo. De fato, a diversificação de produtos que poderiam ser encontrados em um supermercado ao longo dos últimos setenta anos aumentou de modo proporcional ao crescimento das grandes redes de lojas. Estes tipos de organizações comerciais incorporaram neste processo de expansão atividades tais como: utensílios domésticos, perfumaria, bebidas, panificadoras, açougues e diversos outros. O setor de varejo emerge com força no Brasil entre 1950 e 1960, no bojo das ações desenvolvimentistas preconizadas pelos governos de Getúlio Vargas e de Juscelino Kubitschek. Estes governos tinham como objetivo declarado a elevação da renda nacional e, 
consequentemente, a ampliação do consumo no mercado interno. Em decorrência do emergente crescimento do comércio varejista, a competição entre as redes de supermercados de outrora se acentuou, provocando relevante impacto na gestão econômica e financeira destas entidades.

Outra marcante característica do mercado varejista é que este obtém margem líquido muito pequena em relação às receitas de vendas. Assim, os analistas financeiros e outros interessados nas demonstrações contábeis de empresas varejistas, consideram que a margem bruta é um indicador econômico muito importante para mensurar a performance da entidade e que a meta de redução constante de custos deve ser perenemente perseguida.

Cavalcante (2004, p.42) destaca que na guerra por melhores resultados, os grandes conglomerados varejistas passaram a desenvolver técnicas com o objetivo de reduzir seus custos de operação. Para isto, esse tipo de comerciante, de modo confidencial e normalmente individual, passou a se beneficiar de seu poder de barganha para atingir seus objetivos nas negociações com os seus fornecedores. Assim, o ato de comprar passou a ser visto como uma transação em que é possível apurar ganhos ou incorrer em perdas. É através de bonificações comerciais que os fornecedores do setor de varejo estão procurando tornar seus preços atrativos e competitivos, assim como cativar e perpetuar a fidelidade comercial de seus clientes.

A discussão contábil sobre o reflexo de bonificações sobre mercadorias (vendor allowances) nos demonstrativos financeiros das empresas ganhou força após a fraude identificada na US FoodService, uma divisão americana do grupo de varejo holandês Royal Ahold. Os resultados do grupo, oriundo das operações americanas entre os anos de 2000 e 2002, foram superavaliados em US\$880 milhões. A fraude, segundo investigação conduzida pela Securities and Exchange Commission (SEC), ocorreu a partir de um esquema montado entre executivos da FoodService e fornecedores. Os executivos da divisão americana solicitaram aos seus fornecedores nos três exercícios que inflassem os valores a receber oriundos de bonificações sobre mercadorias, nas confirmações de saldos e cláusulas contratuais solicitadas pelos auditores do grupo.

Alguns meses antes deste episódio ter sido divulgado ao mercado, precisamente em novembro de 2002, o Emerging Issue Task Force - EITF, criado para traçar e definir 
diretrizes de implementações de pronunciamentos emitidos pelo Financial Accounting Standard Board (FASB), publicou o EITF - 02-16, para tratar dos aspectos contábeis, pelo comerciante, de certos benefícios recebidos de um fornecedor. Esta orientação definiu alguns parâmetros para reconhecimento de bonificações como recebíveis e do tratamento contábil destes valores no custo das mercadorias adquiridas.

No Brasil, ainda há uma lacuna nas normas contábeis, inexistindo pronunciamentos e posicionamentos formais por parte do Conselho Federal de Contabilidade (CFC), do Instituto dos Auditores Independentes do Brasil (IBRACON) ou da Comissão de Valores Mobiliários (CVM), em relação à contabilização de bonificações sobre mercadorias. Neste vácuo, os auditores independentes de demonstrações contábeis de companhia abertas, por exemplo, têm se socorrido, muitas vezes, das normas adotadas internacionalmente, como o próprio EITF citado anteriormente, adaptadas aos princípios contábeis brasileiros (KPMG, 2003). Por outro lado, um grupo maior, formado por empresas de capital fechado e outras sociedades limitadas que atuam no setor de varejo, estão adotando procedimentos contábeis que nem sempre refletem a essência da transação. Como agravante, tais entidades estão sendo oneradas por uma carga tributária injusta, em decorrência de um tratamento equivocado de fatos contábeis oriundos de bonificações comerciais.

Os fiscos estadual e federal têm manifestado suas posições através de respostas à consultas e emissão destas normativas, algumas vezes até conflitantes, quanto à tributação de determinadas operações de bonificações. Mas a questão principal que vem acirrando disputas entre contribuintes e o fisco é o tratamento de determinadas bonificações como sendo operações condicionais ou incondicionais. A legislação fiscal brasileira, tanto no âmbito federal como estadual, é pacífica quanto à exclusão dos descontos incondicionais da base de cálculo da apuração dos impostos sobre as vendas e sobre os lucros.

No próximo tópico são apresentados os principais tipos de bonificações praticadas entre fornecedores e o setor de varejo, bem como suas implicações e sugestões de registros em conformidade aos princípios contábeis brasileiros e norteamericanos. A identificação e definição destes tipos de bonificações foram obtidas a partir de informativos específicos do setor de varejo e de atos normativos e orientações 
empregados nos Estados Unidos.

\section{DEFINIÇÃO DE BONIFICAÇÕES}

Bonificações são entendidas, por diversos autores no campo de Direito Comercial, como a concessão feita pelo vendedor ao comprador, ao diminuir o preço do produto ou serviço ou entregando quantidades maiores do que as estipuladas contratualmente.

As bonificações, dentro deste contexto, podem ser concessões recebidas tanto em dinheiro como em mercadorias e diferenciam-se de abatimentos, pois segundo ludícibus (1998, p.119), estes são concedidos após as vendas em função de avarias ou outro motivo descoberto a posteriori. As bonificações no setor de varejo estão, na grande maioria das vezes, vinculadas ao desempenho de vendas do varejista, veiculação de propaganda, alteração de preços no mercado ou estratégias promocionais, exposição de mercadorias, dentre outros fatores, e têm forte influência no custo das mercadorias adquiridas.

É importante lembrar o conceito de custo das mercadorias para as considerações a serem efetuadas a seguir. Segundo ludícibus et al. (2003, p.119):

o conceito de custo de aquisição é que deve englobar o preço do produto comprado, mais os custos incorridos adicionalmente, até estar o item no estabelecimento da empresa. Nesse sentido, os custos de embalagem, transporte e seguro, quando por conta da empresa, devem ser considerados como parte do custo de aquisição e debitados a tais estoques.

Para as empresas do setor de varejo que operam com uma grande variedade de produtos, um dos métodos mais comumente empregados é o Método do Preço de Venda a Varejo, em decorrência da dificuldade em se manter um controle de estoque permanente satisfatório. Também conforme definiram ludícibus et al. (2003, p.123):

O método consiste na apuração do total do estoque à preço de venda, quer por meio de contagem física, quer de controles permanentes valorizados aos preços unitários de venda, que são então convertidos a valores de entradas mediante sua multiplicação por quociente médio do custo com relação aos preços de venda a varejo para o período corrente. Essa forma de controle e avaliação representa avaliar estoques finais aos preços 
Há um impasse na legislação e jurisprudência fiscal em relação ao tratamento das bonificações, que a compara aos descontos incondicionais ou condicionais. A Receita Federal, através da Solução de Consulta no․ 159 de 12.09.2003, assim se posicionou:

EMENTA: BONIFICAÇÕES EM MERCADORIAS: As bonificações concedidas em mercadorias, quando constarem da nota fiscal de venda dos bens e não dependerem de evento posterior à emissão desse documento, significam parcelas redutoras da receita de venda (descontos incondicionais).

Já a Secretaria da Fazenda do Estado de São Paulo, através da Decisão Normativa CAT no. 4 de 2000, determina que as bonificações - entendidas como abatimento na forma de mercadoria - devem fazer parte da base de cálculo do ICMS. Assevera este órgão governamental, a exemplo de outros congêneres em diversos estados da federação, que bonificações não se assemelham a descontos incondicionais.

A Lei Kandir exclui da base de cálculo do ICMS os descontos incondicionais. Foi por este motivo, por exemplo, que a Bombril obteve liminar em agosto de 2005, permitindo a exclusão da base de cálculo do ICMS dos valores referentes à bonificações oferecidas em mercadorias aos seus clientes.

Conforme preconiza a legislação estadual em São Paulo, o crédito escritural do ICMS incidente na entrada das mercadorias convertidas em bonificação deverá ser estornado, uma vez que a não incidência configura hipótese de exceção ao aproveitamento do crédito do imposto.

Ainda sob a ótica fiscal, vale mencionar que as mercadorias recebidas como bonificações não proporcionam, também, direito ao crédito de PIS e COFINS pelo regime não cumulativo, já que as mesmas não serão tributadas pela saída dos fornecedores por se tratarem de descontos incondicionais.

Nos casos em que as bonificações forem oferecidas em dinheiro, na forma de reembolso, nos acordos em que sejam estabelecidas condições de quantidades mínimas de compras - e que, historicamente, essas quantidades foram sempre superadas - esses valores a serem recebidos deverão ser provisionados proporcionalmente ao longo do acordo, baseado em compras passadas ou estimativas de compras futuras. 
O EITF 02-16 apresenta o seguinte exemplo ilustrando esse caso:

Em 01 de janeiro de 20X1 o fornecedor oferece, em um acordo comercial, um reembolso de $\$ 1.000$ para um cliente, se durante o ano calendário de $20 \times 1$ este adquirir 1.000 unidades. A média de compras do cliente é de 1.700 unidades cada ano. Avaliação: Desde que ao cliente é garantido receber o reembolso oferecido pelo fornecedor numa compra de 1.000 unidades de estoques, o cliente deve, portanto, registrar a provisão contábil do reembolso sobre as 1.000 unidades, considerando que é provável e razoavelmente estimável que irá comprar as 1.000 unidades durante 20X1.

No exemplo acima, o Princípio da Competência estaria aplicado de forma mais apropriada, ao invés de se tomar o efeito sobre o resultado apenas no mês em que o reembolso fosse concedido.

Nesse caso, no entanto, os valores de reembolso não poderiam ser utilizados para crédito dos tributos não cumulativos em se tratando da operação condicionada.

Caso estes reembolsos fossem oferecidos em forma de mercadorias, caberia uma negociação entre varejistas e fornecedores para se estudar a melhor situação financeira e fiscal para as partes envolvidas.

\subsection{Propaganda Participada}

Propaganda participada é um tipo de bonificação concedida às empresas varejistas pelos fornecedores, para que estas desenvolvam campanhas e materiais publicitários de seus produtos.

Algumas empresas estão tratando estes recursos como uma forma de receita em contrapartida às entradas em caixa, expondo esses recursos à tributação, principalmente em relação ao PIS e a COFINS. O tratamento contábil desses gastos deveria ter efeito apenas entre contas patrimoniais de ativo e de passivo.

A título de exemplo, suponha que determinada empresa $X$ repassou $R \$ 100.000$ de verbas à empresa $Y$ para serem gastas com campanhas publicitárias de seus produtos. $O$ lançamento na contabilidade de $Y$ deveria ser uma entrada de caixa (débito) contra uma obrigação contratual (crédito) no valor do repasse, que irá desaparecer à medida que os recursos forem utilizados.

Este procedimento contábil é válido desde que esse tipo de operação esteja 
formalizado em acordo firmado entre as partes e que a empresa varejista possua controles satisfatórios que identifiquem o valor exato dos gastos de propaganda realizados. Para campanhas comerciais de produtos específicos, isto pode aparentar uma tarefa de pouca dificuldade. No entanto, essa separação ganha maior complexidade a partir do momento que essas campanhas envolvem vários tipos de produtos e fornecedores variados como, por exemplo, anúncios promocionais de determinados produtos de uma rede de supermercados em cadeia de televisão ou produtos anunciados em encartes de jornais.

\subsection{Enxoval/Lançamento de Novos Itens}

Bonificações em forma de enxoval são aquelas oferecidas por fornecedores aos varejistas pela abertura de novas lojas. Este tipo de concessão é bastante comum entre fornecedores e grandes redes de supermercado quando da inauguração de novas filiais. As bonificações por lançamentos de novos itens são geralmente lotes de mercadorias enviadas aos varejistas como forma de divulgar os produtos recém lançados.

O tratamento fiscal e contábil desses estoques recebidos para divulgação deverá ser similar ao tratamento comentado no item 1.1, para as mercadorias recebidas por bonificações de volume, ou seja, deverá ser analisada a situação fiscal em que as mesmas saíram dos fornecedores para se proceder aos devidos registros na contabilidade do varejista.

\subsection{Bônus de Display}

Bônus de display são concessões feitas, geralmente em dinheiro, às empresas varejistas para uma melhor apresentação de seus produtos em vitrines de lojas, prateleiras de supermercados ou locais estrategicamente colocados e com maior proximidade dos consumidores finais.

Uma das dificuldades em se controlar e registrar este tipo de bonificações nos custos das mercadorias adquiridas pelos varejistas é quanto ao problema em associálas a produtos específicos e por períodos de tempos intercalados. Estimativas do número de unidades que serão compradas e vendidas, assim como o giro e dias de 
venda dos estoques, serão fatores críticos na valorização das mercadorias, segundo alerta a Sinopse Contábil elaborada pela KPMG em 2003.

Caso não exista esse controle, uma alternativa seria tratar essas bonificações como redutoras da conta de despesas com vendas, dada a sua natureza. De fato, tal orientação está congruente com o entendimento encontrado em ludícibus et al. (2003, p.348) para este tipo de gasto, ou seja,."as despesas de vendas representam os gastos de promoção, colocação e distribuição dos produtos da empresa, bem como os riscos assumidos pela venda, constando nessa categoria despesas como: com o pessoal da área de vendas, marketing, distribuição,.".

\subsection{Logística}

Os bônus concedidos por logística às empresas varejistas são compensações usualmente fornecidas em dinheiro pelos fornecedores, pelo fato dos mesmos despacharem os produtos vendidos para armazéns indicados pelos varejistas ou centros de distribuição próprios.

A exemplo das bonificações de display, umas das dificuldades deste tipo de concessão é quanto a associação desses recebíveis ao custo das mercadorias adquiridas. As empresas de varejo deverão possuir critérios de rateio e associação satisfatórios para que esses reembolsos sejam devidamente refletidos nos custos dos estoques. Pela impossibilidade em se associar essas bonificações às mercadorias compradas, a empresa deverá proceder a registro similar ao mencionado no item anterior, ou seja, como uma redução de despesas de vendas.

A vantagem deste tipo de operação decorre da possibilidade de obter maior crédito dos valores dos tributos não cumulativos, tais como o ICMS, o PIS e a COFINS. A Tabela 1 demonstra que uma mercadoria adquirida com um desconto financeiro acaba possuindo um custo final menor que aquela comprada com desconto comercial. 
Tabela 1 - Comparação entre desconto comercial e financeiro

\begin{tabular}{|l|l|l|}
\hline & $\begin{array}{l}\text { Desconto } \\
\text { Comercial }\end{array}$ & $\begin{array}{l}\text { Desconto } \\
\text { Financeiro }\end{array}$ \\
\hline Valor bruto da mercadoria & $1.000,00$ & $1.000,00$ \\
\hline Desconto comercial concedido na nota fiscal -15\% & 150,00 & - \\
\hline Desconto financeiro concedido na duplicata - 15\% & - & 150,00 \\
\hline $\begin{array}{l}\text { Custo líquido da mercadoria na nota fiscal } \\
\text { Crédito de ICMS na entrada - 7\% }\end{array}$ & 850,00 & $1.000,00$ \\
\hline $\begin{array}{l}\text { Custo final do produto (valor bruto - desconto - crédito } \\
\text { ICMS) }\end{array}$ & 59,50 & 70,00 \\
\hline
\end{tabular}

\subsection{Proteção de Preço}

Bonificações por proteção de preço são reembolsos feitos pelos fornecedores para garantir as margens comerciais dos varejistas. Esses tipos de acordos são mais comumente encontrados nas empresas que trabalham com produtos de informática e em redes de supermercado. Essa bonificação poderá ser dada como abatimento pelo pagamento de compras, como créditos de compras futuras ou com o reembolso em dinheiro ou em mercadorias.

Esse tipo de acordo comercial não apresenta tanta complexidade na alocação do valor da bonificação aos custos dos produtos adquiridos, diferentemente das bonificações por display ou logística. Deverá se ter cuidado, no entanto, quanto à forma de registro, pois deverá ser contemplado com a subtração de custos cada um dos tipos de modalidade de ressarcimento citados no parágrafo anterior, assim como deverá ser efetuado o estorno dos impostos não cumulativos pelas diferenças de numerário recebidas do fornecedor.

Os tipos de bonificações exemplificados neste trabalho não esgotam todas as modalidades de acordos comerciais em uso. Existem outras variedades de contratos firmados entre indústria e varejo, tais como: bônus por aderência e respeito à cláusulas de despacho, pagamentos por exclusividade, salário de promotores e expositores e outros.

O ponto crucial destas outras variações é o de se buscar entender o verdadeiro reflexo de cada tipo de concessões em relação aos custos das mercadorias adquiridas, de maneira tal que essas operações possam ser corretamente associadas, classificadas e registradas de acordo com os princípios contábeis brasileiros. 
Caso essas associações não sejam possíveis, nem tampouco essas bonificações venham a ter relação direta com determinadas mercadorias, as empresas deverão identificar a real natureza dessas operações e reconhecê-las na rubrica mais apropriada do balanço patrimonial ou demonstração de resultado, prevalecendo, sempre, a essência sobre a forma.

\section{ORIENTAÇÕES CONTÁBEIS DO FASB}

O Financial Accounting Standard Board - (FASB), preocupado com as dificuldades enfrentadas pelos contadores norte-americanos no processo de identificação, mensuração, registro e divulgação das receitas ou ganhos decorrentes de acordos comerciais entre fornecedores e varejistas, que proporcionam os diversos tipos de bonificações anteriormente identificadas, se pronunciou, através do seu grupo de tarefas emergenciais - Emerging Task Issues Force - no sentido de estabelecer um método comum de tratamento contábil para esses tipos de transações financeiras.

Em decorrência, foi publicado o EITF №. 02-16 - Accounting by a Customer (Including a Reseller) for Certain Consideration Received from a Vendor, que, em tradução livre poderia ser assim entendida: Contabilização por parte do Cliente (Inclusive Revendedor) de Certas Contraprestações Recebidas de Fornecedores.

A manifestação do FASB justifica-se, uma vez que a margem bruta de vendas dos varejistas se constitui em importante elemento nas análises do desempenho econômico e financeiro deste tipo de atividade. A forma de registro da recuperação de custos, bem como a rubrica contábil eleita para tal ato, pode apresentar o reconhecimento de ganhos ou receitas não efetivamente realizados sob o mandato do princípio contábil da competência dos exercícios.

O EITF №. 02-16 orienta que todas as bonificações recebidas de um fornecedor por um varejista devem ser reconhecidas como uma redução do custo dos produtos vendidos (conta de compras no resultado do período) e/ou como redução dos saldos patrimoniais de estoques, dos estoques é alterada nas seguintes circunstâncias relacionadas pelo pronunciamento do FASB em tela: 


\subsection{Bonificação Recebida em Contrapartida da Prestação de Serviços ou Entrega de Bens pelo Comprador ao Fornecedor}

Este tipo de bonificação pode ser caracterizada como receita do exercício. Todavia, além da demanda no sentido de ser factível a identificação clara do tipo de bonificação percebida, este benefício pode ser, ainda, registrado contabilmente como outras receitas em uma determinada transação de compra considerando os seguintes critérios: a) o fornecedor poderia ser capaz de adquirir produtos ou contratar esses serviços de um terceiro; b) o varejista possui condições de estimar razoavelmente o valor justo dos bens ou serviços prestados ao fornecedor, em contrapartida às bonificações recebidas.

Os serviços de transporte entre o centro de distribuição do supermercado, por exemplo, e suas lojas, pode ser um dos exemplos desses tipos de bonificações percebidas, já que, via de regra, os fornecedores preferem entregar grandes quantidades de produtos nos centros de distribuição dos varejistas, para que estes se encarreguem de distribuí-los para suas lojas.

\subsection{Recuperação de Despesas}

A recuperação de despesas ocorridas na operação de varejo, especificamente identificadas no esforço das vendas dos produtos ou dos serviços prestados, pode ser classificada como uma subtração dos valores registrados daquelas despesas específicas. Um exemplo desse tipo de bonificação são as verbas de marketing cobradas aos fornecedores para cobrir os custos com a preparação de tablóides e comerciais de TV produzidos para divulgar as promoções do varejista, que, na realidade, promovem os produtos anunciados e, indiretamente, as marcas dos seus fornecedores participantes.

Também, como citado no item anterior, a diferença a maior entre o valor recebido pelo varejista da bonificação e o valor efetivo da despesa que está sendo recuperada deve ser contabilizado como redução de custo das mercadorias vendidas ou custo de aquisição das mercadorias que ainda se encontram em estoque.

Há casos, ainda, em que os fornecedores efetuam acordos para conceder bonificações aos varejistas em decorrência de, por exemplo, um evento relativo a 
um período de tempo específico futuro, ou quando do atendimento de certas condições, como por exemplo: a) se o varejista permanecer como cliente do fornecedor por um determinado período de tempo, ou; b) se o varejista mantiver níveis de compras em determinados montantes estabelecidos contratualmente entre as partes compradora e vendedora, etc. Essas bonificações, geralmente, são contabilizadas apenas quando tais condições são atendidas. Todavia, orienta o FASB, o varejista pode reconhecer os valores da transação em bases pro rata tempore, desde que possua controles internos adequados para garantir que os valores apropriados sejam razoavelmente estimados e que os mesmos tenham reais possibilidade de vir a ser recebidos futuramente.

Faz-se oportuno, ainda, mencionar que o EITF №. 02-16 cita alguns cenários que, se constatados nesse tipo de estimativa de cálculo de bonificação, podem inviabilizar o reconhecimento pro rata tempore dessas bonificações. Os cenários exemplificados pelo FASB são os seguintes: a) as metas por serem atingidas entre as partes são definidas para períodos muito longos de tempo, como, por exemplo, na situação em que o varejista tem de permanecer comprando do referido fornecedor por diversos anos; b) ausência de histórico de compras de produtos similares ou mudança no cenário mercadológico, de modo que a experiência pregressa existente no relacionamento entre as partes possa não ser mais confiável e razoável no futuro; c) histórico de erros nas estimativas de períodos anteriores nesse tipo de bonificação, bem como existência de erro na previsão de valor justo ou falha na expectativa de recebimento de bonificações em períodos anteriores, e; d) susceptibilidade do produto a fatores externos, como obsolescência ou sazonalidade.

Em síntese, o FASB entende que se a bonificação não for passível de ser estimada em bases razoáveis, ou seu recebimento não for provável, esta não deverá ser reconhecida no resultado do exercício da entidade varejista. Nestas circunstâncias, o registro contábil deverá ser feito somente quando do efetivo recebimento da bonificação.

As mudanças na estimativa das bonificações futuras, e as mudanças retroativas das condições inicialmente acordadas devem ser reconhecidas utilizando o conceito "ajuste catch- up acumulado", qual seja, todo efeito financeiro e contábil deverá ser refletido nos registros contábeis no momento em que a entidade definiu fazê-lo. Tal 
ajustamento é realizado pelo varejista com base na diferença de valor apurada entre as condições atuais e àquelas anteriormente acordadas e com base no volume já reconhecido. O montante apurado da distorção entre os valores estimados e aqueles ocorridos de fato deve ser lançado tão logo seja consagrado o cenário, de uma única vez no custo das mercadorias vendidas, ou reduzindo o custo de aquisição de mercadorias que ainda se encontrem em estoques.

\section{CONSIDERAÇÕES FINAIS}

A variedade de concessões em forma de bonificações discutidas neste trabalho pode reduzir significativamente os custos de compras, despachos, exposição, logística, marketing e tributários das empresas que atuam no setor de varejo.

Essas empresas, com todo o seu poderio de compras, atuando como os principais canais de vendas dos produtos de grandes fornecedores de itens de consumo, podem utilizar esta força para captar e intensificar formas existentes de acordos comerciais, assim como desenvolver novas frentes de negociação. Contudo, é importante frisar o correto reconhecimento destas bonificações nas demonstrações contábeis para que as mesmas reflitam a fiel situação patrimonial e financeira da empresa em termos de valorização dos custos dos estoques e das mercadorias vendidas, e para que não ocorra tributação indevida sob essas operações.

Três principais passos deverão ser dados nesse sentido pelas empresas varejistas: a) identificar os diferentes tipos de acordos comerciais comumente utilizados por natureza de operação (volume, logística, propaganda participada, financeiro, display, enxoval, etc.); b) segregar as bonificações em condicionais ou incondicionais; c) formalizar junto a todos os fornecedores as condições comerciais de cada acordo e adotar os procedimentos acessórios necessários em termos fiscais; e, d) implantar um processo de controle de bonificações capaz de registrar seus efeitos de forma tempestiva, completa e irretratável.

Depois de tomadas essas medidas, as empresas que atuam no setor de varejo estarão caminhando em linha com práticas contábeis já internacionalmente em uso. $O$ que ainda é mais interessante em termos financeiros é que essas entidades poderão 
reduzir assim sua carga tributária, que pode estar sendo calculada sobre os recursos totais recebidos em dinheiro, considerando, por óbvio, que o governo mantenha as regras atuais de tributação.

Restará, assim, apenas aos órgãos contábeis brasileiros competentes regulamentar ou formalizar suas interpretações quanto a esses procedimentos, para que os mesmos sirvam como balizamento para todo o setor varejista e para os seus fornecedores, bem como para os auditores independentes de demonstrações contábeis destas entidades, no sentido de ganharem nas normas contábeis um respaldo formal dos procedimentos revisados.

\section{REFERÊNCIAS}

CAVAlCANTE, L.B. 2004. Poder de Compra do Varejo Supermercadista: Uma Abordagem Antrituste. Monografia de MBA em Direito Econômico e das Em presas. Fundação Getúlio Vargas, 42 p.

Emerging Issues Task Force (EI TF). 2002. Accounting by a Customer (Including a Reseller) for Certain Considerations Received from a Vendor. EI TF 02- 16, nov. Disponível em: http: / / www.fasb.org, acesso em 25/ 06/2005.

Emerging Issues Task Force (EI TF). 2002. Application of Issue №. 02-16 by Resellers to Sales Incentives Offered to Consumers by Manufacturers. EI TF 03- 10, nov. Disponível em: http: / / www.fasb.org, acesso em 25/ 06/ 2005.

FABRETTI, C. 2005. Contabilidade Tributária. 9ª ed. São Paulo, Atlas, p. 48.

FOOD AND DRI NK EUROPE. Nine Charged in Ahold Fraud Case. Disponível em http: / / www.foodanddrinkeurope.com / news/ news- ng. asp?n= 57354- ninecharged-in, acesso em 31/ 08/2005.

IUDÍCIBUS, S. (Org.). 1998. Contabilidade Introdutória. 9ª ed., São Paulo, Atlas, p. 119.

IUDÍCIBUS, S., MARTI NS E. e GELBCKE, E.R. 2003. Manual de Contabilidade das Sociedades por Ações. 6aㅡ ed. São Paulo, Atlas, p. 119,123 e 348.

KPMG. Sinopse Contábil 2003. Disponível em http: / / www.kpmg.com.br/adm/im ages/sinopse\% 20contábil\% 2003_SI TE.pdf, acesso em 28/ 08/ 2005.

RECEITA FEDERAL. Solução de Consulta no 159 de 12/ 09/ 2003. Disponível em http: / / decisoes.fazenda.gov.br, acesso em 21/ 08/ 2005. 
Bonificações no setor de varejo - receita ou redução de custos?

Jerônimo Antunes, Vinícius de Castro Alves Sampaio

Data de Submissão: 09/02/2007

Data de Aceite: 28/02/2007 